\title{
Alinhamento estratégico entre o planejamento urbano municipal e a gestão da mobilidade e dos equipamentos públicos urbanos
}

\author{
Strategic alignment between the urban municipal planning and \\ management of mobility and urban public equipment
}

\section{Luiz Aurélio Virtuoso $^{[\mathrm{a}]}$, Jansen Maia Del Corso $^{[\mathrm{b}]}$, Isabel Cristina da Costa Domingues ${ }^{[\mathrm{c}]}$}

[a] Mestre em Administração Estratégica pela Pontifícia Universidade Católica do Paraná (PUCPR), professor do Departamento de Transportes do curso de Engenharia Civil da Universidade Federal do Paraná (UFPR), engenheiro civil da Unidade de Programação Operacional do Transporte Coletivo da URBS, Curitiba, PR - Brasil, e-mail: lvirtuoso@urbs.curitiba.pr.gov.br

[b] Professor do Doutorado em Administração da Pontifícia Universidade Católica do Paraná (PUCPR), Curitiba, PR - Brasil, e-mail: del.corrso@pucpr.br

[c] Mestranda em Administração Estratégica pela Pontifícia Universidade Católica do Paraná (PUCPR), Curitiba, PR - Brasil, e-mail: isabeladv@bol.com.br

\section{Resumo}

O presente artigo tem como objetivo avaliar o alinhamento entre a estratégia do Instituto de Pesquisa e Planejamento Urbano de Curitiba-IPPUC, responsável pelo planejamento urbano municipal, e a estratégia da Urbanização de Curitiba S/A - URBS, responsável pela gestão da mobilidade urbana e dos equipamentos públicos urbanos na cidade de Curitiba. Trata-se de uma pesquisa descritiva de natureza qualitativa, cujos métodos de coleta e tratamento dos dados foram a entrevista semiestruturada, a pesquisa documental e a transcrição das entrevistas. O propósito da pesquisa é de um estudo descritivo. Os resultados obtidos demonstraram que a URBS e o IPPUC atuam em conjunto no desenvolvimento do macroplanejamento do sistema viário, do transporte coletivo e dos projetos dos equipamentos urbanos que depois serão gerenciados pela URBS. Percebeu-se, também, que existe uma administração estratégica formal nas duas empresas, necessitando de melhorias na fase de implantação e de controle. Quanto ao alinhamento estratégico entre as duas empresas, observou-se que as estratégias estão alinhadas, visando à melhoria da vida urbana. $\mathrm{O}$ processo de alinhamento estratégico é sustentado pelo Plano de Governo Municipal, pela direção política do prefeito do município, pela lei de responsabilidade fiscal e pelos programas de financiamento, em que a URBS, como futura gestora, participa dos projetos elaborados pelo IPPUC.

Palavras-chave: Alinhamento estratégico. Planejamento urbano. Organizações públicas. 


\begin{abstract}
The main objective of the present article is to evaluate how the alignment between the Curitiba Institute of Urban Development Research strategy - IPPUC, responsible for the municipal urban planning, and the Curitiba Urbanization S/A strategy - URBS, responsible for the management of mobility and the urban public equipment in Curitiba, takes place. This is a descriptive research with qualitative characteristics whose the data collection method and treatment used was semi-structured interview, documentary research and interviews transcription. This research aims to be a descriptive study. The results show that URBS and IPPUC act together developing the road system macro planning, the public transportation and the urban equipment projects that later will be managed by URBS. There is formal strategic management in the two companies, however it needs improvement in the control and in the implementation phases. As for the strategic alignment between the two companies, it can be observed that there are lined up strategies, seeking to improve the urban life. The strategic alignment process is supported by the City Government Plan, by the mayor politics management, by the Fiscal Responsibility Law, and by the financing programs, where URBS, as future manager, takes part in the projects elaborated by IPPUC.
\end{abstract}

Keywords: Strategic alignment. Urban planning. Public organizations.

\section{Introdução}

As pessoas atualmente vivem das e nas organizações, sejam elas grandes ou pequenas, privadas ou públicas, pois hoje são um componente predominante na sociedade contemporânea. De acordo com Drucker (1974), surge uma sociedade de organizações, onde as tarefas sociais importantes estão a cargo de uma grande instituição.

A complexidade das organizações exige que a sua vida seja coordenada por pessoas ou órgãos com funções chamadas de administração e, mais recentemente, de gestão. As organizações, buscando desempenhar um gerenciamento eficaz em um ambiente cada vez mais exigente, necessitaram desenvolver novas técnicas gerenciais. Por isso, as escolas de administração responderam a essas necessidades e a estratégia tornou-se cada vez mais importante na pesquisa de administração.

Dentre os tipos de organizações existentes, destacamos as públicas. No Brasil, essas organizações estão distribuídas nos níveis federal, estadual e municipal. A gestão das organizações públicas municipais está relacionada com todas as suas dimensões, isto é, com a gestão da prefeitura e de seus órgãos, institutos, autarquias e secretarias.

Com o aumento das exigências por parte dos cidadãos e dos desafios sociais, políticos e orçamentários, o município necessita desenvolver uma estratégia integrada com seus órgãos, institutos, autarquias e secretarias, devendo ser compatibilizados entre si, resultando em uma abordagem equilibrada entre eles (REZENDE; CASTOR, 2005).

Com base nas considerações expostas até o presente momento, este estudo está voltado a responder a seguinte questão de pesquisa: como se dá o alinhamento entre a estratégia do IPPUC, responsável pelo planejamento urbano municipal, e a estratégia da URBS, responsável pela gestão da mobilidade urbana e dos equipamentos públicos urbanos na cidade de Curitiba?

A importância desta pesquisa está no fato de descrever como essas organizações públicas municipais criam, formulam e implementam suas estratégias na busca de atender aos anseios da sociedade moderna. O estudo busca também caracterizar o processo que leva ao alinhamento, ou até mesmo ao desalinhamento, dessas estratégias. $\mathrm{O}$ trabalho pode ser justificado em função de que o IPPUC e a URBS tomam decisões que influenciam o espaço e a mobilidade urbana, afetando diretamente a população, a indústria, o comércio e os serviços de Curitiba e de toda a sua região metropolitana.

O presente artigo está dividido em cinco tópicos que podem ser sumarizados da seguinte forma: a primeira seção refere-se à introdução; a segunda seção traz o referencial teórico sobre os temas abordados nesta pesquisa; a terceira seção é dedicada à metodologia aplicada na realização deste estudo; a quarta seção trata da apresentação e análise dos resultados; e na quinta seção são realizadas as considerações finais e as recomendações para trabalhos futuros. 


\section{Suporte téorico}

\section{Alinhamento estratégico}

$\mathrm{Na}$ literatura existem conceitos básicos relacionados ao alinhamento estratégico e, ainda, algumas abordagens de gestão estratégica que utilizam o conceito de alinhamento estratégico. Esses conceitos e abordagens são apresentados a seguir.

O termo "alinhamento estratégico" e o seu conceito básico surgiram nas empresas de tecnologia da informação (TI). Por muito tempo, as empresas de pequeno, médio e grande porte adquiriram e implantaram softwares e sistemas de informação de apoio à gestão, sem verificar a real necessidade em relação às suas estratégias. Como consequência, apresentou-se pouca utilização desses programas computacionais e um alto custo em relação ao seu baixo benefício. Nesse panorama, a gestão de TI emprega o alinhamento estratégico visando a estabelecer uma relação entre o planejamento da tecnologia da informação e o planejamento estratégico das empresas. Com base nos autores sobre gestão de TI, a definição de alinhamento estratégico diz respeito ao grau de adequação entre os processos e os recursos de TI existentes na organização e a estratégia de negócios. Essa definição representa o foco somente no alinhamento entre processos de TI e a estratégia da empresa (REZENDE, 2002; 2003).

Kaplan e Norton $(2000,2005,2006)$ estão entre os primeiros a utilizar o termo alinhamento na gestão estratégica. O balanced scorecard (BSC) tem como propósito alinhar a organização com a estratégia, ou seja, alinhar os recursos organizacionais com os processos críticos da empresa e estes com o posicionamento estratégico da empresa. Como resultado, a organização obteria o máximo valor para seus acionistas por meio de estratégias específicas de produtividade e acréscimo de receita. Essa definição dos autores explica que uma empresa alinhada com a estratégia alcança desempenho financeiro acima da média dos seus concorrentes.

Outro conceito relacionado ao alinhamento encontra-se nos estudos de Mintzberg et al. (2006). O autor oferece uma metáfora, em que a organização é representada por uma plataforma de lançamento, os produtos e serviços são os projéteis, os quais são lançados para um determinado local (mercado) onde estão os alvos (clientes/mercados), enfrentando os rivais (ou concorrência), na busca do ajuste (posição estratégica).

Já os estudos de Cordeiro (2005) apresentam algumas abordagens existentes na literatura que visam a uma maneira de avaliar o grau de alinhamento entre os contextos e a estratégia, buscando ajudar nas ações tomadas no contexto da gestão estratégica. $\mathrm{O}$ autor apresenta três abordagens: o gerenciamento pelas diretrizes, os modelos dos prêmios de qualidade e o balanced scorecard. Essas abordagens tratam de como alinhar a organização e suas diversas funções e processos a uma determinada estratégia, podendo ser utilizadas no sentido de avaliar se uma determinada organização está alinhada.

A primeira abordagem apresentada pelo autor é uma das principais ferramentas de gestão estratégica das empresas japonesas que têm como objetivo transformar as estratégias da organização em realidade, isto é, implementá-las. Esse método é de responsabilidade da alta administração e necessita da participação de todos, visando à sobrevivência da organização no longo prazo.

A segunda abordagem apresentada pelo o autor - os prêmios de qualidade - torna explícita a definição de categorias de desempenho e estabelecimento de relação de causa e efeito entre elas. Os três prêmios citados pelo autor são: Malcolm Baldrige Award, Prêmio Europeu de Qualidade e Prêmio Nacional da Qualidade. Cordeiro (2005) explica que os três modelos de prêmios de qualidade vinculam a formulação e a implementação de estratégias aos resultados obtidos pela organização.

Esses três modelos, na visão do autor, não têm como ambição explicar as relações de causa e efeito que relacionam a estratégia ao desempenho organizacional, porém, deixam clara a necessidade do alinhamento entre os recursos e processos com a estratégia, e o alinhamento desta com o contexto externo, para o alcance das metas financeiras. Entretanto, não são fornecidos meios para visualizar que recursos devem ser qualificados para melhorar o desempenho de quais processos, os quais seriam responsáveis pela entrega do valor proposto pela empresa aos seus clientes (CORDEIRO, 2005). E como ferramenta para resolver esse problema, Cordeiro (2005) apresenta o BSC como a terceira abordagem para avaliar o alinhamento estratégico.

OBSC é um sistema de controle, criado por Kaplan e Norton (2005), que consiste em parâmetros financeiros complementados com indicadores 
operacionais de satisfação do cliente, processos internos, atividades de inovação e aprimoramento da empresa, o que dá à alta gerência uma visão rápida, mas abrangente da empresa. O gerente, por meio do BSC, avalia quatro perspectivas: como o cliente nos vê? (perspectiva do cliente); em que devemos atingir a excelência? (perspectiva interna da empresa); como acentuar e gerar valor continuamente? (perspectiva de inovação e aprendizado); que imagem os acionistas fazem da empresa? (perspectiva financeira). Dessa maneira, esse sistema fornece dados aos gerentes de quatro perspectivas diferentes, porém, sem excesso de informação.

Cordeiro (2005) explica que o BSC tem como ponto de partida o estabelecimento da missão, da visão e dos objetivos estratégicos de uma organização. Ressalta-se, também, que para elaborar esse sistema é fundamental definir a estratégia da organização. Assim, o BSC seria uma ferramenta que deveria ser utilizada para implementação da estratégia, principalmente pela dificuldade de fazê-la por parte de diversas organizações.

$\mathrm{Na}$ literatura revisada, o termo "alinhamento estratégico" representa alinhar (ou sincronizar) a organização propriamente dita. Os autores apresentados mostram como alinhar recursos internos e externos com a estratégia, competências com recursos, estratégia com PIs, e mais uma gama de combinações entre elementos que formam a organização e o seu meio ambiente. Contudo, para o presente estudo, que busca verificar a existência do alinhamento entre as estratégias, os recursos e as competências entre duas organizações, não foi localizada literatura específica para o tema abordado, razão pela qual o estudo realizado é de caráter exploratório.

Essas teorias apresentadas servirão, entretanto, como base para a pesquisa, a qual mostrará se as estratégias adotadas pela URBS e pelo IPPUC possuem uma sincronia, istoé, se suas atividades estão alinhadas e como ocorre o processo de alinhamento estratégico entre elas, com o propósito de melhorar a condição da vida urbana na cidade de Curitiba.

\section{Metodologia da pesquisa}

A questão base desta pesquisa é analisar “como se dá o alinhamento entre a estratégia do IPPUC, responsável pelo planejamento urbano municipal, e a estratégia da URBS, responsável pela gestão da mobilidade e dos equipamentos públicos urbanos na cidade de Curitiba", fazendo-se necessário coletar dados sobre as atividades que cada organização exerce; quais as atividades em que atuam conjuntamente; como se desenvolve o processo estratégico; o alinhamento entre as estratégias das organizações e quais os fatores que levam a esse alinhamento.

As perguntas de pesquisa foram: que funções desempenham as entidades URBS e IPPUC? Em quais atividades a URBS e o IPPUC atuam conjuntamente? Como se desenvolve o processo estratégico na URBS e no IPPUC? Como se caracteriza o processo de alinhamento estratégico entre URBS e IPPUC?

Já as variáveis estudadas neste trabalho foram: processo estratégico e alinhamento estratégico.

Esta pesquisa limitou-se em pesquisar o alinhamento estratégico somente nas organizações públicas municipais de Curitiba que atuam no planejamento urbano municipal - o IPPUC - e na gestão da mobilidade, do equipamento urbano e dos espaços públicos municipais - a URBS.

A natureza da presente pesquisa é qualitativa, visando a obter dados descritivos sobre pessoas, lugares e processos, buscando compreender os fenômenos por meio dos atores da situação em estudo. A investigação foi realizada utilizando a classificação proposta por Cooper e Schindler (2003), pela qual o presente trabalho pode ser considerado como uma pesquisa exploratória, graças à necessidade de utilização de estruturas livres que possibilitem desenvolver hipóteses ou questionamentos para pesquisas futuras. O método de coleta de dados, segundo os autores, foi o de interrogação/comunicação, em que o pesquisador questiona os sujeitos e coleta as respostas por meios pessoais ou impessoais.

Quanto à capacidade do pesquisador controlar as variáveis, a pesquisa caracteriza-se por ser ex-post-facto. Quanto ao propósito da pesquisa, trata-se de um estudo descritivo. O estudo revela quem, o que, quando, onde e quanto o estudo está relacionado à questão da pesquisa que questiona sobre tamanho, forma, distribuição ou existência de uma variável.

O presente trabalho teve como dimensão do tempo o estudo transversal, que é conduzido apenas uma vez e revela um "instantâneo de um determinado tempo" (COOPER; SCHINDLER, 2003, p. 129). Este trabalho é caracterizado como um estudo de 
caso, pois a pesquisa envolve mais ênfase na análise total do contexto de poucos eventos ou condições e suas inter-relações. Optou-se, ainda, pelo estudo de caso por garantir maior validade externa para as relações sugeridas quando analisadas amplamente (KERLINGER, 1980).

Na presente pesquisa, as unidades de análise foram duas entidades: o IPPUC e a URBS. Quanto ao tipo de coleta de dados, estes foram coletados em fontes primárias e secundárias. Os dados primários foram obtidos por meio de entrevistas semiestruturadas, por ser uma técnica de pesquisa rica e flexível e, também, por ser a mais indicada para os métodos qualitativos (COLLIS; HUSSEY, 2005). As fontes de coleta de dados foram compostas pelo presidente do IPPUC em exercício no ano de 2008; pelo ex-presidente do IPPUC, o qual exerceu suas funções no ano de 2005 e, atualmente, é diretor de desenvolvimento na URBS; pela diretora de trânsito da URBS e pelo gestor do transporte coletivo da mesma entidade. Os critérios estabelecidos para selecionar os entrevistados foram: ter conhecimento sobre a estratégia da empresa; conhecer ou atuar nas atividades conjuntas entre o IPPUC e a URBS; aceitar participar deste estudo.

Os dados secundários foram obtidos por meio de análise documental que foi feita em documentos oficiais ou não das organizações, nas publicações, nos periódicos, nos relatórios teóricos e operacionais das atividades. Também foram pesquisados dados disponíveis para consulta na bome page das instituições pesquisadas e nos trabalhos científicos realizados sobre as organizações públicas municipais estudadas.

A análise dos dados ocorreu simultaneamente ao levantamento e registro, possibilitando ao pesquisador avaliar os dados colhidos e decidir sobre a necessidade de revisar ou aprofundar os conceitos. Os dados primários coletados nas entrevistas, por meio de gravação da entrevista e de anotações, foram transcritos. Na sequência, foi realizada uma análise do conteúdo das respostas dos entrevistados e, também, dos dados secundários levantados na análise documental, buscando identificar as atividades de cada empresa e as atividades conjuntas das organizações, descrever o processo estratégico de cada empresa e caracterizar o processo de alinhamento estratégico entre as duas empresas.

\section{Apresentação e análise dos resultados}

A presente seção divide-se em duas subseções. Na primeira são apresentadas as informações sobre as duas empresas estudadas, obtidas na análise dos dados capturados a partir das entrevistas semiestruturadas realizadas e na análise dos documentos disponibilizados e acessíveis. $\mathrm{Na}$ segunda são apresentados e analisados os resultados da pesquisa, relacionando as informações obtidas com a referência teórica do presente estudo.

\section{Apresentação das empresas}

O IPPUC foi criado na gestão do prefeito Ivo Arzua Pereira (1962-1966) como uma autarquia municipal. A missão institucional do IPPUC é:

coordenar o processo de planejamento e monitoramento urbano da cidade, compatibilizando as ações do município às da Região Metropolitana, na condução do desenvolvimento sustentável. Para isso, elabora pesquisas, planos, projetos e programas, capta recursos para a implantação de programas dos órgãos da administração direta e indireta da Prefeitura Municipal de Curitiba, buscando a excelência em planejamento urbano (IPPUC, 2008).

E os objetivos estratégicos:

- Ordenar o crescimento da Cidade com a distribuição adequada das atividades urbanas;

- Criar soluções integradas, visando melhores condições sociais e econômicas da população;

- Articular as políticas e diretrizes setoriais que interfiram na estruturação urbana do Município e da Região Metropolitana;

- Captar recursos e atrair investimentos para viabilizar a implantação de planos, programas, projetos e obras do Município (IPPUC, 2008).

Atualmente, além da função básica de pesquisa e planejamento, o IPPUC é responsável por: coordenar as ações do Plano de Governo Municipal; coordenar a elaboração e acompanhar a implantação 
do Plano de Obras; produzir, agregar e analisar informações relativas a indicadores sociais; produzir e coordenar a execução de projetos de arquitetura, comunicação visual e mobiliário urbano; coordenara integração das diretrizes locais de planejamento com as diretrizes metropolitanas e disseminar as práticas desenvolvidas em Curitiba, por meio da participação em eventos nacionais e internacionais e de visitas e cooperação técnica com instituições, cidades e países de todo o mundo (IPPUC, 2008).

A URBS foi criada em 1963, com o objetivo de administrar o Fundo de Urbanização de Curitiba e com o passar dos anos passou a gerenciar serviços de táxi, transporte comercial, transporte coletivo de passageiros de Curitiba e região metropolitana - o trânsito no Município de Curitiba (URBS, 2008).

A missão da empresa consiste em:

Melhorar a vida urbana.

Para o cidadão queremos proporcionar mobilidade, soluções e serviços de excelência com rapidez, conforto, segurança e baixo custo.

Para a Administração Pública queremos ser o melhor parceiro para solucionar demandas públicas com agilidade, transparência, ética, responsabilidade e custo acessível.

Para nossos colaboradores queremos ser motivo de orgulho e oferecer satisfação pessoal e profissional, valorização, reconhecimento compatível com seu desempenho, perspectiva de crescimento profissional e boas condições de trabalho.

Para as entidades públicas e privadas interessadas nas nossas soluções queremos ser referência e modelo a ser seguido.

Para nossos fornecedores queremos ser cliente exigente e proporcionar oportunidades de negócio compatíveis com nossa missão e nossos valores.

Para os nossos permissionários queremos proporcionar oportunidades de negócio e exigir excelência de serviços ao cidadão em consonância com nossos valores (URBS, 2008).

E os objetivos consistem em:

Melhorar a eficiência e a qualidade dos serviços de transporte de passageiros, trânsito, equipamentos urbanos e espaços públicos de Curitiba.
Buscar o equilíbrio econômico-financeiro dos serviços prestados.

Ampliar a capacidade do sistema de transporte coletivo e do trânsito (URBS, 2008).

Atualmente, as principais atividades da URBS são o planejamento e gerenciamento dos serviços de transportes; o planejamento, gerenciamento e operação dos serviços de trânsito; e a administração, manutenção e comercialização do uso de equipamentos públicos urbanos.

\section{Análise dos dados coletados}

\section{Atividades conjuntas do IPPUC e da URBS}

Dentre todas as atividades exercidas pela URBS e pelo IPPUC descritas anteriormente, observou-se que nos dias de hoje o IPPUC e a URBS atuam conjuntamente nas atividades ligadas ao macroplanejamento do sistema viário, da circulação viária, do transporte coletivo e dos projetos referentes aos equipamentos urbanos. As atividades conjuntas entre os dois órgãos poderiam ser definidas de acordo com o gestor do transporte coletivo: "O IPPUC planeja e a URBS executa".

A URBS e o IPPUC, em conjunto com outras secretarias do governo municipal, definem o Plano de Governo, que, conforme exposto por Andrade et al. (2005), expressa o planejamento de médio prazo, evidenciando os programas de trabalho por um período de quatro anos. A última versão do Plano de Governo apresenta sete eixos estratégicos que expressam o planejamento da atual gestão, em que a URBS e o IPPUC atuam diretamente nos eixos "mobilidade urbana", "integração metropolitana" e "infraestrutura, urbanismo e meio ambiente".

A respeito da existência de um limite onde terminam as atribuições do IPPUC e começam as atribuições da URBS, identificou-se que essa divisão de atribuições não está totalmente definida. O critério utilizado para definir de quem é a competência de um determinado projeto é baseado em quem possui a melhor estrutura para executar ou contratar. A decisão é tomada em reuniões entre a URBS e o IPPUC, em que se combina, sempre de comum acordo, quem executa. 


\section{Processo estratégico}

O IPPUC e a URBS, apesar de atuarem de maneira conjunta em muitas atividades, desenvolvem o processo estratégico separadamente, de acordo com a gestão vigente.

Ao analisarmos a estrutura organizacional do IPPUC, conforme abordado por Hall (2004), o primeiro aspecto visível é a sua complexidade, contando com uma estrutura com vários títulos de cargos. Quanto ao segundo aspecto, observou-se que o IPPUC tem como característica ser uma empresa descentralizada. O instituto representa ser uma organização formalizada, principalmente em decorrência do Plano de Governo estabelecido pela atual gestão. Quanto à sua estrutura, com base nos estudos de Harrison (2005), constatamos, ao analisarmos o organograma da empresa, que esta possui uma estrutura funcional. Analisando o IPPUC, conforme exposto por Mintzberg, Ahlstrand e Lampel (2000), a configuração da estrutura está entre a profissional e a adhocracia.

Sobre a cultura organizacional do IPPUC, percebeu-se que apresenta características básicas das organizações em geral, contudo a sua cultura é formada por alguns elementos, apresentados por Carbone (2000), que identificam uma cultura de organização pública: o autoritarismo, a aversão aos empreendedores, o paternalismo, o reformismo e a descontinuidade dos governos.

De acordo com as escolas do pensamento estratégico apresentadas por Mintzberg, Ahlstrand e Lampel (2000), o IPPUC adota características da Escola do Poder, da Escola Cognitiva e da Escola do Design.

O processo estratégico do IPPUC está relacionado com o Plano Plurianual, a Lei de Diretrizes Orçamentárias e a Lei Orçamentária Anual do município. De acordo com o exposto por Andrade et al. (2005), o IPPUC expressa o planejamento de médio prazo, evidenciando os programas de trabalho para o período da gestão municipal, em sete eixos estratégicos. A direção estratégica do IPPUC, de acordo com Harrison (2005), está representada pela missão, pelos objetivos estratégicos e funções que se divulgam pelo site do Instituto na internet.

Na presente pesquisa, não foi constatada a existência de um sistema de controle formal da empresa. No entanto, o governo municipal e o IPPUC devem cumprir o art. 165 da Constituição Federal, que trata sobre PPA, LDO e LOA, que são instrumentos que aliam o planejamento ao orçamento público, de acordo com o exposto por Andrade et al. (2005).

Quanto ao pensamento estratégico do IPPUC, de acordo com os estudos de Harrison (2005), está baseado no fato de a organização considerar a cidade como um ser vivo e em constante mutação, na busca incessante de soluções inovadoras para os problemas urbanos e no conhecimento adquirido pelas gerações anteriores (PMC, 2008).

Já a URBS, para o cumprimento de todas as suas competências, desenvolveu uma estrutura organizacional, conforme abordado por Hall (2004), na qual se observa a divisão em hierarquias e diferentes cargos. Nela observaram-se as três características estruturais expostas por Hage (1965): complexidade, centralização e formalização.

A cultura organizacional percebida na URBS, conforme apresentada por Pires e Macêdo (2006), mantém basicamente as características de uma organização privada, porém, demonstra algumas das características expostas pelos autores que fazem a URBS se diferenciar como uma organização pública, sendo observado o burocratismo, o paternalismo e a presença de um quadro permanente e outro não permanente. A descontinuidade gerada pela mudança do quadro permanente ocasiona na URBS, de acordo com o citado por Schall (1997), projetos de curto prazo, duplicação de projetos e conflitos de objetivos entre os dois corpos funcionais.

A estratégia adotada pela URBS é decorrente do processo de realinhamento estratégico iniciado em 2005. De acordo com a definição de Mintzberg (2006), observou-se que a estratégia da empresa tem características entre posição e plano. $\mathrm{O}$ processo estratégico da empresa, de acordo com Mintzberg, Ahlstrand e Lampel (2000), apresentaram características da Escola de Design. Entretanto, observou-se que a estratégia da URBS tende a ser um processo de transformação contínua depois do realinhamento estratégico, aproximando-se das características da Escola de Configuração.

O processo de administração estratégica da URBS mostrou ser formado pelos conceitos expostos por Harrison (2005), resultado de uma consultoria contratada pela URBS ao desenvolverum planejamento formal da estratégia e de pensamento estratégico, em que a empresa busca soluções criativas e novas ideias para melhor atender ao público interessado. 
A formulação da estratégia foi desenvolvida nos três níveis, conforme abordagem de Harrison (2005). No nível corporativo foi observado que a URBS adotou uma estratégia de concentração, buscando fazer muito bem o seu principal negócio, a mobilidade urbana. Quanto ao nível empresarial, a URBS demonstrou melhorar os seus recursos visando à sustentabilidade da empresa, adotando uma estratégia de baixo custo, isto é, buscando equilibrar a oferta de melhores serviços aos seus PIs com baixo custo. No nível funcional, foram identificadas duas áreas para iniciar a implantação da estratégia de nível empresarial, consideradas primordiais para a empresa: transporte coletivo e financeiro. $\mathrm{Na}$ área do transporte coletivo, a ação está baseada basicamente na remodelagem do sistema integrado de transporte público da cidade, com o objetivo de melhorar a oferta do transporte coletivo para reter o usuário atual e conquistar novos usuários. O trabalho da área financeira consiste em buscar novas fontes de recursos para a empresa, além da principal: a taxa cobrada pela empresa, proveniente da administração do transporte coletivo e das multas de trânsito.

O processo estratégico da empresa está no nível de implantação. Para monitorá-lo, bem como as suas atividades, a empresa está buscando uma nova consultoria para estabelecer os sistemas de controle da estratégia necessários para a manutenção da administração estratégica da URBS.

\section{Alinhamento estratégico entre IPPUC e URBS}

No IPPUC e na URBS, observou-se que os objetivos estratégicos das duas empresas têm o mesmo norte: planejamento urbano eficiente para melhorar a mobilidade urbana e, consequentemente, a qualidade de vida dos cidadãos. Como já observado anteriormente na elaboração do Plano de Governo de Curitiba, a URBS e o IPPUC trabalham em conjunto na definição das principais diretrizes da gestão. Esse processo, somado à direção política determinada pela gestão do prefeito municipal, resulta em um passo inicial para o alinhamento estratégico.

Quando são realizadas as atividades do macroplanejamento do transporte coletivo urbano, observa-se que ocorre um esforço conjunto entre URBS e IPPUC para a definição das atividades relacionadas a esse planejamento, discutindo o que cada um irá realizar dentro das suas possibilidades.

Em relação ao trânsito, inicialmente o seu gerenciamento era realizado pelo IPPUC. Essas competências foram repassadas para a URBS e os técnicos passaram a trabalhar nessa instituição, ocupando cargos de chefia e de gerência, criando um vínculo entre as duas organizações.

Outro ponto observado que leva ao alinhamento e à criação da área de operação de trânsito, o resultado da observação parte da diretoria de trânsito da estrutura da área de transporte, a qual possui uma unidade de operação, entendendo ser necessário ter uma área análoga na setor de trânsito, a fim de realizar melhor as atividades competentes ao trânsito.

$\mathrm{Na}$ URBS, criou-se dentro da Diretoria de Trânsito a área de mobilidade, visando a integrar os projetos de transporte e trânsito dentro da URBS, bem como fazer a interface com o IPPUC. Essa mudança resultou em uma série de ações em relação a novas ligações urbanas e na criação de um sistema integrado de mobilidade (SIM) ena Central de ControleOperacional (CCO), integrando o trânsito e o transporte.

Quanto aos equipamentos urbanos, a URBS tem como responsabilidade a administração da rodoferroviária, de terminais de ônibus, das ruas da cidadania, do Centro Comercial Rui Barbosa, do Shopping Popular, do Mercado Central, das Arcadas de São Francisco e da Rua 24 Horas, os quais foram planejados pelo IPPUC e estão em operação até os dias de hoje, com exceção da Rua 24 Horas, que atualmente está passando pela remodelação de sua estrutura.

A respeito da comunicação entre IPPUC e URBS, observou-se que atualmente acontece por meio de reuniões pontuais, marcadas para resolverem assuntos específicos. Outro meio de comunicação é a utilização do sistema Lotus Notes, ferramenta da IBM que serve para mensagens eletrônicas, como comunicador instantâneo, navegador, entre outros recursos. Também se faz o uso do e-mail do servidor da prefeitura municipal, porém, em segundo plano, principalmente porque o Notes estava mais difundido entre os funcionários.

\section{Considerações finais, limitações e recomendações}

Ao analisar as atividades desenvolvidas em cada organização, percebeu-se que estão claramente 
definidas e não existe sobreposição de competências. Observou-se, também, que para a URBS desenvolver o gerenciamento do trânsito e do transporte pode existir sobreposição de atividades, e quando isso acontece, busca-se, por meio de reuniões, a definição em conjunto de quem será responsável em desenvolvê-las.

Identificou-se no estudo, dentre as atividades do IPPUC e da URBS, que os dois órgãos atuam em conjunto no desenvolvimento do macroplanejamento do sistema viário, da circulação viária, do transporte coletivo e dos projetos dos equipamentos urbanos que depois serão gerenciados pela URBS.

Em relação aos controles burocráticos, conclui-se que são extremamente necessários para o desenvolvimento das atividades da URBS: programação operacional do transporte coletivo e programação semafórica; controle na arrecadação do vale transporte, evitando fraudes e falsificações; operação do transporte coletivo; controle do quilômetro rodado; pagamento desse custo para as empresas que operam o sistema do transporte coletivo; implantação de equipamentos urbanos; e demais atividades competentes dessa instituição.

$\mathrm{Na}$ URBS, o processo estratégico é decorrente do realinhamento estratégico realizado na empresa em 2005. Com isso, essa instituição estabeleceu uma nova missão e novos objetivos, mas não ocorreram mudanças nas suas competências.

$\mathrm{Na}$ estrutura organizacional, ocorreram mudanças significativas. Foi criada a diretoria de novos negócios, atualmente diretoria de desenvolvimento, com a função de executar a gestão de patrimônio, de novos empreendimentos, e a de relacionamento da empresa. A assessoria jurídica foi transformada em diretoria jurídica. No trânsito, foi criada a gerência de operação de trânsito, seguindo os moldes da estrutura da diretoria de transportes, além da criação da área de mobilidade urbana, com a função de integrar os projetos internos da empresa e ser responsável em fazer uma interface com o IPPUC.

Observou-se que existe uma grande preocupação tanto no IPPUC quanto na URBS em relação à estratégia empresarial. Nessa questão, as duas empresas apresentam um alinhamento entre seus objetivos, que é oferecer melhor qualidade de vida aos cidadãos. Entretanto, existem falhas no processo de implantação da estratégia e praticamente não existe um mecanismo de controle de estratégia.
Quanto ao processo de alinhamento estratégico entre a URBS e o IPPUC, foi observado que este se inicia já na elaboração, em conjunto, das ações do Plano de Governo, bem como está relacionado com LDO, LOA E PPA. Esses mecanismos contribuem para que ocorra um alinhamento entre as estratégias do IPPUC e da URBS. O aspecto financeiro, principalmente quanto à Lei de Responsabilidade Fiscal, que estabelece limite no grau de endividamento dos municípios, também leva as duas organizações a ter que tomar decisões alinhadas.

$\mathrm{Na}$ área do transporte, observou-se que um dos fatores de alinhamento relaciona-se ao fato de que, como cabe à URBS operar o transporte coletivo urbano, as questões operacionais são fundamentais no momento da realização dos projetos que são de competência do IPPUC. Nos projetos ligados ao transporte, se as entidades citadas não caminharem juntas, não existe como executá-los. Na área de trânsito, um dos fatores que alicerçaram o alinhamento estratégico se deu quando o novo Código de Trânsito Brasileiro municipalizou o serviço de trânsito, resultando na criação da Diretoria de Trânsito (Diretran) e os funcionários do IPPUC que atuavam nessa área passaram a ser da URBS, criando-se um canal de comunicação informal, baseado no relacionamento das pessoas.

O alinhamento estratégico também ocorre quando há necessidade de financiamentos de projetos por meio de bancos ou agências de desenvolvimento. Para a liberação do financiamento, essas instituições estabelecem normas que devem ser seguidas, as quais consideram questões socioambientais, normas técnicas e leis municipais, desde a elaboração do projeto, passando pela execução e se estendendo até o momento da finalização e entrega da obra.

Observou-se, neste estudo, que a área do transporte coletivo da URBS possui um alinhamento maior com o IPPUC, se comparado com o alinhamento da área de trânsito da URBS com o IPPUC. Nesse fato, é importante observar que a URBS foi capaz de diagnosticar o problema e de providenciar uma solução, com a criação da área de mobilidade, visando a criar uma sinergia entre as atividades dos dois órgãos. Percebeu-se também que, em alguns momentos, as áreas de trânsito e transporte conversavam diretamente com o IPPUC e não entre si. Essa nova área também criou uma integração maior entre as áreas internas da URBS. 
O alinhamento entre URBS e IPPUC se alicerça também na direção política determinada pela prefeitura municipal, nas reuniões em que são decididos projetos em conjunto e na constante comunicação que ocorre na troca de mensagens eletrônicas via Notes. O alinhamento estratégico entre as duas empresas não é perfeito. Influências políticas, problemas de relacionamento entre técnicos e a falta de uma gestão de informação tornam os processos mais lentos.

Entretanto, ao verificar as melhorias na infraestrutura como: criação dos binários, gerando novas ligações viárias; pavimentação e recuperação das vias; obras da Linha Verde; investimentos em sinalização vertical e horizontal; semaforização dos cruzamentos; melhoria na frota do transporte coletivo, com ônibus novos e motores menos poluentes; criação de novas linhas de ônibus; implantação da linha "Ligeirão Boqueirão"; campanhas de educação no trânsito; reformas nos terminais de ônibus; investimento em tecnologias que permitam a priorização do transporte público em relação ao transporte individual, entre outras ações, e contando ainda com o crescimento populacional de Curitiba e Região Metropolitana e o aumento da frota de veículos observado nos últimos anos, atingindo o índice de 1,7 carros por habitante, observa-se que a URBS e o IPPUC, de forma conjunta, buscam cumprir o principal objetivo, que é a melhoria da vida das pessoas no meio urbano.

Para que a questão do alinhamento entre o IPPUC e a URBS melhore e tenha continuidade, o estudo sugere inicialmente que as atividades do IPPUC e da URBS devem ser definidas em conjunto não só entre os dois órgãos, e sim numa discussão ampla com todos os públicos interessados nos dois órgãos. Depois de uma definição clara do que compete a cada empresa, sugere-se a ampla divulgação das novas atribuições.

Mecanismos de comunicação devem ser melhorados a fim de que as decisões que concernem às duas empresas sejam tomadas em conjunto, evitando o desperdício de recursos e de tempo. Isso pode ser feito com a implementação de um sistema de informações gerenciais integrado entre as duas empresas.

$\mathrm{Na}$ estrutura organizacional, os cargos de comissão devem ser ocupados por funcionários com base técnica, evitando que pessoas despreparadas assumam funções de gestão importantes, diminuindo o controle político, fazendo com que as decisões sejam tomadas baseadas em dados técnicos.

Esta pesquisa apresenta as seguintes limitações: a primeira refere-se ao momento político eleitoral no tempo programado para a realização das entrevistas. Algumas pessoas previamente selecionadas para a pesquisa não conseguiram disponibilizar um horário nas suas agendas por causa de compromissos políticos. O presidente do IPPUC não conseguiu disponibilizar um tempo adequado para a realização da entrevista semiestruturada, porém, contribuiu com a pesquisa, cedendo as respostas por meio de e-mail.

A segunda limitação está relacionada à influência da subjetividade do pesquisador na análise e discussão dos dados. O uso de diversas fontes de dados e teorias e um processo cuidadoso de confirmação das categorias que emergiram na análise dos dados foi a maneira encontrada para minimizá-la.

O terceiro ponto limitador diz respeito aos documentos disponibilizados para a análise dos dados. Estes foram, basicamente, no formato de jornais e revistas institucionais e, ainda, materiais na forma de leis e decretos. Outro ponto que deve ser considerado como um limitador na pesquisa é a ausência, na bibliografia nacional e internacional pesquisada, de outras pesquisas relacionadas ao tema.

O IPPUC e a URBS necessitam de evolução dos quadros de gestão, e para isso devem investir em programas de treinamento e capacitação, resultando na preparação e no aprimoramento desses profissionais, desenvolvendo não só conhecimento técnico, mas também habilidades gerenciais, deixando de viver dos louros do passado e resgatando a capacidade de enxergar o futuro e de imaginar uma nova cidade.

Outra sugestão é o IPPUC e a URBS buscarem a certificação pelas normas ISO. Esse processo traria uma normalização de suas atividades, registrada em manuais de procedimentos. Esse conhecimento passaria a ser registrado e explicado, não se perdendo com o desligamento de funcionários, e também facilitaria o processo de treinamento na admissão de um novo funcionário.

As informações e o conhecimento não podem ficar retidos dentro das unidades e das áreas. A sugestão é a gestão do conhecimento. Com isso, além de evitar a perda de conhecimento quando acontece o desligamento de um funcionário, permitese que o conhecimento fique disponível a todos na organização. 
Quanto ao processo estratégico, a URBS e o IPPUC necessitam desenvolver mecanismos que auxiliem na implantação da estratégia e no seu efetivo controle. Isso pode ser obtido, inicialmente, por meio de consultorias especializadas e, na sequência, com a capacitação de funcionários, visando à criação de uma assessoria responsável pelo processo estratégico e, principalmente, pela implementação e controle da estratégia. Esse processo estratégico deve buscar desenvolver e aperfeiçoar as alianças estratégicas entre a URBS e os seus principais públicos interessados, tais como as empresas de ônibus que operam o sistema do transporte coletivo, as empresas que prestam serviço relacionados à rede semafórica e à sinalização viária, fornecedores e permissionários dos equipamentos públicos.

O presente estudo analisou e caracterizou o processo de alinhamento estratégico somente entre duas organizações públicas de Curitiba. Novos estudos podem ser realizados entre outros órgãos da esfera municipal da cidade estudada, ou de qualquer outra cidade, ou, ainda, pode haver a realização de um estudo abrangente sobre o alinhamento estratégico entre a prefeitura municipal de Curitiba e suas secretarias, órgãos e autarquias, demonstrando quais estão mais ou menos alinhados e quais os processos que os sustentam.

\section{Referências}

ANDRADE, N. A. et al. Planejamento governamental para municípios: plano plurianual, lei de diretrizes orçamentárias e lei orçamentária anual. 2. ed. São Paulo: Atlas, 2005.

CARBONE, P. P. Cultura organizacional no setor público brasileiro: desenvolvendo uma metodologia de gerenciamento da cultura. Revista de Administração Pública, Rio de Janeiro, v. 34, n. 2, p. 133-144, mar./abr. 2000.

COLLIS, J.; HUSSEY, R. Pesquisa em administração: um guia prático para alunos de graduação e pós-graduação. 2 ed. Porto Alegre: Bookman, 2005.

COOPER, D. R.; SCHINDLER, P. S. Métodos de pesquisa em administração. 2. ed. Porto Alegre: Bookman, 2003.
CORDEIRO, J. V. B. M. Alinhamento estratégico: estudos multicasos em empresas paranaenses de médio porte. 2005. 300 f. Tese (Doutorado em Engenharia de Produção) - Universidade Federal de Santa Catarina, Florianópolis, 2005.

DRUCKER, P. F. Uma era de descontinuidade. 2. ed. Rio de Janeiro: Zahar, 1974.

HAGE, J. An axiomatic theory of organization. Administrative Science Quarterly, v. 10, n. 3, p. 289320, 1965.

HALL, R.H. Organizações: estrutura, processos e resultados. 8. ed. São Paulo: Pearson Education do Brasil, 2004.

HARRISON, J. S. Administração estratégica de recursos e relacionamentos. 2. ed. Porto Alegre: Bookman, 2005.

INSTITUTO DE PESQUISA E PLANEJAMENTO URBANO DE CURITIBA - IPPUC. Planejamento urbano de Curitiba. Disponível em: <http://www. ippuc.org.br/ippucweb/sasi/home/mostrarpagina. php?pagina $=1$ \&idioma=1>. Acesso em: 10 maio 2008 .

KAPLAN, R. S.; NORTON, D. P. Having trouble with your strategy? Then map it. Harvard Business Review, v. 4, n. 4, p. 58-69, 2000.

KAPLAN, R. S.; NORTON, D. P. Balanced scorecard: medidas que movem o desempenho. 2. ed. Rio de Janeiro: Campus, 2005.

KAPLAN, R. S.; NORTON, D. P. Alinhamento: utilizando o balanced scorecard para criar sinergias corporativas. 2. ed. Rio de Janeiro: Campus, 2006.

KERLINGER, F. N. Metodologia de pesquisa em ciências sociais: um tratamento conceitual. 2. ed. São Paulo: EPU, 1980.

MINTZBERG,H.;AHLSTRAND, B.;LAMPEL,J. Safári de estratégia: um roteiro pela selva do planejamento estratégico. Porto Alegre: Bookman, 2000.

MINTZBERG, H. et al. O processo da estratégia: conceitos, contextos e casos selecionados. 4. ed. Porto Alegre: Bookman, 2006.

PIRES, J. C. S.; MACÊDO, K. B. Cultura organizacional em organizações públicas no Brasil. Revista de Administração Pública, v. 40, n. 1, p. 81-105, jan./ fev. 2006. 